\title{
ECLETICA
}

www.scielo.br/eq

www.ecletica.iq.unesp.br

Volume 32, número 4, 2007

\section{Synthesis and characterization of activated carbon fibers from Kevlar}

\author{
L. Giraldo ${ }^{a}$, Y. Ladino ${ }^{b}$, J.C M. Pirajánc , M. P. Rodríguez ${ }^{b}$ \\ ${ }^{a}$ Faculty of Sciences, Department of Chemistry, Universidad Nacional de Colombia. \\ ${ }^{b}$ Faculty of Science and technology. Dep.Chemistry. Univ.Pedagógica Nacional. Bogotá, Colombia. \\ 'Faculty of Sciences, Department of Chemistry, Research Group of Porous Solids and Calorimetry, Universidad de Los Andes, \\ Bogotá, Colombia. \\ *jumoreno@uniandes.edu.co
}

\begin{abstract}
Kevlar [poly (p-phenilylene terephtalamide)], was used as a precursor in the preparation of activated carbon fibers. For this intention, physical and chemical activations were carried out. Activated fibers were physically prepared from the carbonization of the Kevlar and its later activation with $\mathrm{CO}_{2}$ and steam of water, by the other hand; the chemically activated fibers were obtained by means of the impregnation of the material with phosphoric acid and their later carbonization. Different conditions were used and preliminary analyses of the precursor were taken into account (TGA-DTA / IR). The resulting fibers were characterized by $\mathrm{N}_{2}(77 \mathrm{~K})$ adsorption, infrared spectroscopy, SEM, and immersion calorimetry. Yields and Burn off were also evaluated. The results shows that if you want to synthesize activated carbon fibers from Kevlar strong conditions respect to the commonly used such as water steam, high phosphoric acid concentrations and methods of impregnation are the ones who allows the development of optimal surface areas and pore volumes.
\end{abstract}

Keywords: Kevlar; activated carbon fibers; physical activation; chemical activation; characterization.

\section{Introduction}

During the last decades, new alternatives and technologies showing appropriate properties to reduce environmental pollution at a very low level have been developed, being lead of the most common contaminant present in water streams and air. Alternatives as the use of granular activated carbon (GAC), powdered activated carbon (PAC) and activated carbon fiber (ACF) have been widely implemented due to the increasing demand of this type of materials. Activated carbon fibers are one of the called "new materials" and because of their characteristics, have been used for a wide range of applications as: Operation of air conditioning systems, creation of personal protection and, in the chemical industry, for the protection of wounds by semi-permeable band aids that do not allow micro organisms access and for removing VOCs (benzene, acetone, dichloromethane, nhexane, acrylonitrile, etc.) $[1,2]$.

Activated carbon fibers offer several advantages in comparison with GACs and PACs. Micropores mainly constitute the ACF porous structure, while other presentations of activated carbons have a complex structure formed by micropores, mesopores and macropores. The diameters of the ACFs are smaller $(10-40 \mu \mathrm{m})$ than the ones of GAC and PAC particles, providing a greater adsorption rate. Another advantage of the ACFs is that the distance among fibers may be controlled by selecting the precursor material to allow ACFs to be packed in bed fixed adsorbents. In the same way, ACFs are excellent adsorbents due to their lowpressure fell, high contact efficiency and flexibility, lightness and malleability. 
Feedstock materials for ACFs are usually of low crystallinity, such as viscose rayon, polyacrylonitrile, or coal tar pitch [3]. Alternatively, aramid fibers have also been proposed as high cristallinity precursors and some studies haven been reported using as precursor Nomex and Kevlar [4, 5, 6, 7].

Kevlar fiber, synthesized in 1979 by $\mathrm{Du}$ Pont, is an organic fiber in the aromatic polyamide family. The unique properties and distinct chemical composition of wholly aromatic polyamides (aramids) distinguish them from other commercial, man- made fibers [8]. It is use in bulletproof vest and suits resistant to high temperatures.

In this study, activated carbon fibers were prepared by physical and chemical activations. The fist ones were prepared using $\mathrm{CO}_{2}$ and water steam. The second ones were prepared through the impregnation of the precursor with phosphoric acid using different conditions. Both processes are evaluated and considerations are made respect to the behavior of the precursor and the obtained fibers.

\section{Experimental details}

\section{Physical Activation}

The starting material was Kevlar. Pyrolysis was carried out in a vertical quartz reactor, in which 3 - $4 \mathrm{~g}$ of the precursor were introduced. Temperature was programmed lo increase at a rate of $4^{\circ} \mathrm{C}$ up to 800,900 and $1000^{\circ} \mathrm{C}$, under a $\mathrm{N}_{2}$ flow (80 $\left.\mathrm{cm}^{3} \mathrm{~min}^{-1}\right)$. After pyrolysis, the activation was carried out. First $\mathrm{CO}_{2}$ was used $\left(50 \mathrm{~cm}^{3} \mathrm{~min}^{-1}\right)$, at temperatures $50^{\circ} \mathrm{C}$ below the pyrolysis one. The activation was carried out at different time intervals ( 3 and 6 hours) to achieve different degrees of burn off (BO). Then, the agent was changed by steam of water (flows of 3 and 8 drops per minute) at $750^{\circ} \mathrm{C}$ and times of 1 and 2 hours respectively.

\section{Chemical activation}

The fibers were impregnated using 3 - $4 \mathrm{~g}$ of Kevlar and $100 \mathrm{ml}$ of an aqueous solution of $\mathrm{H}_{3} \mathrm{PO}_{4}$ of different concentration in order to vary the impregnation ratio. Besides different conditions of impregnation were used: Room temperature for 24 hours; $90^{\circ} \mathrm{C}$ for 7 hours and finally a rotary evaporator guaranteeing la homogeneous impregnation of the material. After that, the impregnated samples were died overnight at $110^{\circ} \mathrm{C}$ in a vacuum furnace. All the activations were done in a quartz reactor using 3-4 g of impregnated Kevlar, a flow of $\mathrm{N}_{2}$ $\left(80 \mathrm{~cm}^{3} \mathrm{~min}^{-1}\right)$ and a heating rate of $10^{\circ} \mathrm{Cmin}^{-1}$ until $700^{\circ} \mathrm{C}$; once this temperature was attained, the samples were rapidly cooled down to room temperature. The resulting carbons were washed in a soxhlet extractor to remove the activating agent and/or its decomposition products.

\section{Characterization techniques}

Studies of mass loss as a function of temperature were made by thermogravimetry (TG) and differential thermogravimetry (TGA) in a Netzsch STA 409 PC, using $100 \mathrm{mg}$ of sample, and a heating rate of $10^{\circ} \mathrm{Cmin}^{-1}$, between room temperature and $1000^{\circ} \mathrm{C}$. IR spectra were obtained in a Nicole Nexus FT-IR looking for the chemical changes in the fibers through the different processes. SEM studies were carried out in the activated fibers; the samples were not coated with a conducting material prior to examination.

In the other hand, the porous texture of ACFs was analyzed by physical adsorption of $\mathrm{N}_{2}$ at $77 \mathrm{~K}$ measured in a volumetric adsorption apparatus Autosorb 3-B (Quantachrome). Prior to the analysis, the samples were outgassed overnight under vacuum at $423 \mathrm{~K}$. The $\mathrm{N}_{2}$ data were analyzed according to the BET method to calculate the specific surface area, and the Dubinin Raduschkevich (DR) equation to calculate the micropore volume. Finally, the heats of immersion of the samples into $\mathrm{C}_{6} \mathrm{H}_{6}$ were determined at $298 \mathrm{~K}$ with a Calvet calorimeter. The samples $(\sim 0.1 \mathrm{~g})$ were outgassed prior to the analysis.

\section{Results and discussion}

\section{Thermogravimetric Analysis (TG-DTA)}

Fig. 1 shows the TG-DTA curves for the raw and carbonized fiber. For the first one, TG curve shows a weight loss ascribable to release of moisture at $200^{\circ} \mathrm{C}$. In addition, a big weight loss occurs between $550-650^{\circ} \mathrm{C}$; it is related to the pyrolisis of the material. In this point a $55.19 \%$ of weight loss is attained and the change of color is notable (Initially the fiber is yellow). At temperatures between 700 and $900{ }^{\circ} \mathrm{C}$ exists another weight loss. It is smaller than the other ones. Finally, if fibers are subjected to temperatures close to $1000^{\circ} \mathrm{C}$ the weight loss will be nearly to $68.8 \%$ from the initial mass.

In contrast, the curve obtained for the carbonized material presents a different behavior. It is possible to see a weight loss at temperatures from 


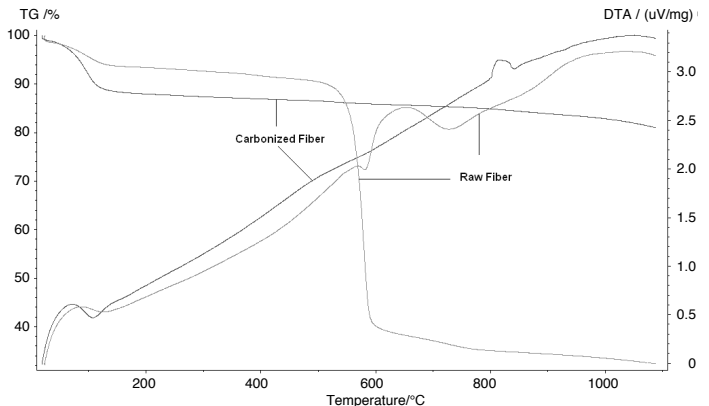

Figure 1. TGA-DTA curves for raw and carbonized Kevlar.

$20^{\circ} \mathrm{C}$ to $200^{\circ} \mathrm{C}$, which indicates that at the beginning of the activation the major weight of loss takes place. This process involves a weight of loss corresponding to $11.99 \%$. In general, above $200^{\circ} \mathrm{C}$ there are no any big weight losses, however, it is possible to appreciate that the decomposition and association processes still continuous. It is also evident that in the process of carbonization is where the greatest losses of weight occurs on the material, while at the subject again the carbonized fiber at high temperatures (in the activation process) there is no significant mass loss. This implies that the time more than temperature activation is an important variable in preparing fibers.

In addition, Fig. 2 shows the behavior of the impregnated fiber with $\mathrm{H}_{3} \mathrm{PO}_{4}$ respect to the raw one. We appreciate weight losses close to $100^{\circ} \mathrm{C}$ and $550^{\circ} \mathrm{C}$ corresponding to loss of moisture and pyrolysis processes respectively. The residual mass will be $44.98 \%$ of the initial mass at temperatures close to $1100{ }^{\circ} \mathrm{C}$ or so. Although both seem similar curves, impregnated fiber changing mass is slightly less than in the raw fiber showing that the presence of the acid allows higher yields.

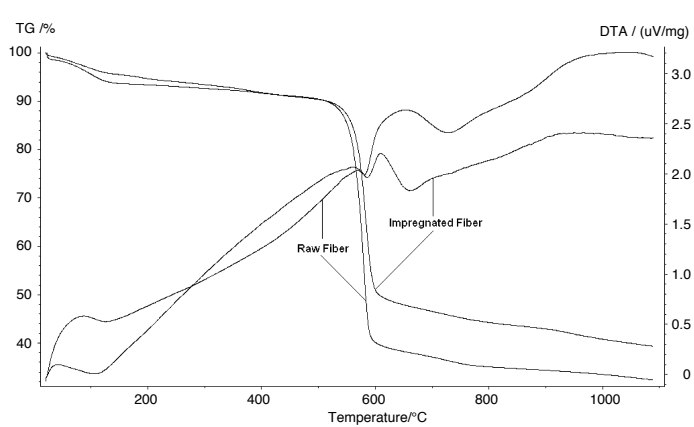

Figure 2. TGA-DTA in raw and Kevlar fibers impregnated with $\mathrm{H}_{3} \mathrm{PO}_{4}$.
Fu et al [1,2], reported that upon thermal treatment of fibers impregnated with $\mathrm{H}_{3} \mathrm{PO}_{4}$ the activating agent was volatilized in different phosphorus compounds to such an extent that the washing step to remove it became less and less crucial to open the porosity and could even be omitted for a sample prepared at $800^{\circ} \mathrm{C}$. Because of the temperature chose in this work $\left(700^{\circ} \mathrm{C}\right)$ this phenomena was looked in the washing step, the $\mathrm{pH}$ stabilized quickly.

\section{Infrared spectroscopy (IR)}

Regarding changes in the chemical surface groups Fig. 3 shows the variations from the raw fiber, and the carbonized and physically activated ones. For the first, the peaks correspond to the chemical formula of Kevlar [poly (p-phenilylene terephtalamide)] ) $\left.\left(\mathrm{C}_{14} \mathrm{H}_{11} \mathrm{O}_{2}\right)_{\mathrm{n}}\right): 3400,1500$ and $1300 \mathrm{~cm}^{-1}$ for $\mathrm{N}-\mathrm{H}$ stretching corresponding to the secondary amines with aromatic rings; $1600,1100,800$ and $900 \mathrm{~cm}^{-1}$ for benzene rings with substitution $p$. The band in $1641 \mathrm{~cm}^{-1}$ refers to bonds $\mathrm{C}=\mathrm{O}$; and $1530 \mathrm{~cm}^{-1}$ for stretching C$\mathrm{N}, \mathrm{N}-\mathrm{H}$ and $\mathrm{C}-\mathrm{N}-\mathrm{H}$. The peaks in the spectrum in the region between 900 and $2000 \mathrm{~cm}^{-1}$ confirms the presence of aromatic rings. In addition, a band at $2400 \mathrm{~cm}^{-1}$ indicates the occurrence of aryl nitrile bonds $(\mathrm{N} \equiv \mathrm{C})$.

For the carbonized fiber, the reduction in the number of band implies a regrouping of the molecules in the fiber. In the same way, the spectrum shows the presence of groups $\mathrm{N}-\mathrm{H}$ at $3400 \mathrm{~cm}^{-1}$. The band that excels at $1624 \mathrm{~cm}^{-1}$ can be attributed to vibrations $\mathrm{C} \equiv \mathrm{C}$ of polynuclear aromatic hydrocarbons or aromatic compounds replaced by functional groups with heteroatoms. In addition, small vibrations present below $900 \mathrm{~cm}^{-1}$ may be due to vibration $\mathrm{C}-\mathrm{H}$ atoms of hydrogen in contiguous

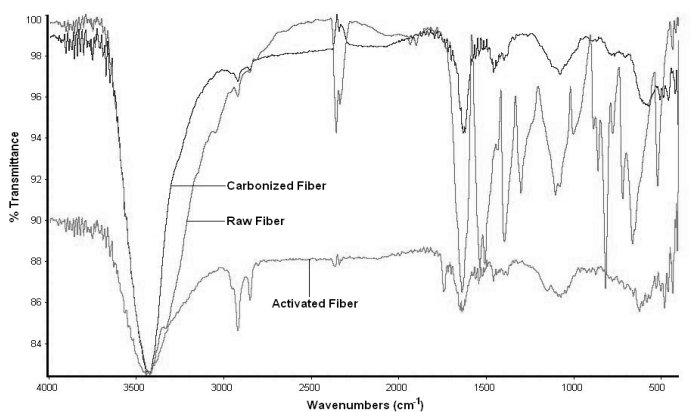

Figure 3. IR of raw, carbonized and physically activated fibers. 
polynuclear aromatic compounds confirming the occurrence of polycondensation reactions [6].

The physically activated fiber presents a spectrum similar respect to the carbonized fiber. However, it is important to emphasize one peak near to $2800 \mathrm{~cm}^{-1}$. This latter type of vibration represents the area of triple bond specifically the $\mathrm{N} \equiv \mathrm{C}$ one (aryl nitrile) which is formed along the pyrolysis process [9].

In turn, Fig. 4 shows the change in Kevlar fiber after the chemical activation with phosphoric acid. The peaks of the spectrum are: $3400 \mathrm{~cm}^{-}$ 1 for $\mathrm{N}-\mathrm{H}$ links; $2922 \mathrm{~cm}^{-1}$ to $\mathrm{C}-\mathrm{H}$ unions. Again, a band appears in $2361 \mathrm{~cm}^{-1}$ which refers to aryl compounds formed in the pyrolysis and more at temperatures close to the activation one $\left(700^{\circ}\right.$ C). The vibration submit to $1624 \mathrm{~cm}^{-1}$ indicates $\mathrm{C}$ $=\mathrm{O}$ bonds, while the peaks present between 1000 and $900 \mathrm{~cm}^{-1}$ implies the existence of P-O-C, P$\mathrm{OH}, \mathrm{P}-\mathrm{C}$ (aromatic), $\mathrm{PO}_{2}$ and $\mathrm{PO}_{3}$ groups proceeds from the presence of phosphoric acid and its interaction with the molecules of the fiber in the carbonization process.

\section{$\mathrm{N}_{2}$ adsorption isotherms}

The starting material is a non porous fiber

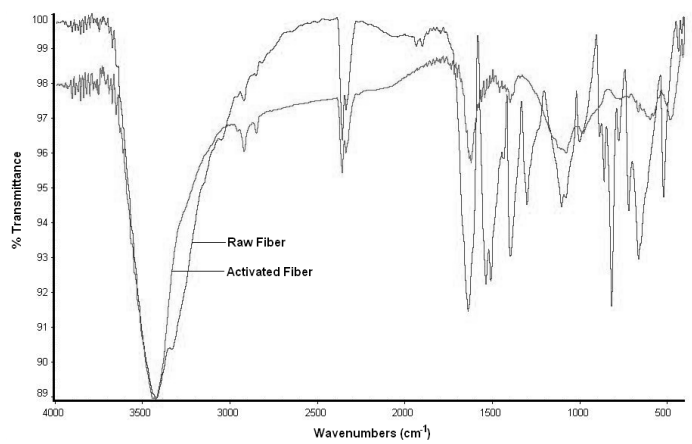

Figure 4. IR for the raw and activated fiber with phosphoric acid. with a $\mathrm{S}_{\mathrm{BET}}=0.0072 \mathrm{~m}^{2} / \mathrm{g}$. Fig. 5 shows the $\mathrm{N}_{2}$ isotherms for physically activated fibers with $\mathrm{CO}_{2}$ at $850^{\circ} \mathrm{C}$ and steam of water at $750^{\circ} \mathrm{C}$ at several degrees of activation (BO) using different times. The temperature of activation with steam of water was chosen because it presented the best yields and BO. All isotherms are type II in the IUPAC classification, suggesting the existence of macropores on the fibers surface. The low increase of the slope suggests that the external surface does not change much with the activation degree [3].

Table 1 gives the textural parameters calculated from $\mathrm{N}_{2}$ adsorption at $77 \mathrm{~K}$. The data shows that the increase in the time of activation and BO do not imply an increase in the surface area of the carbon fiber. Although this is not a common behavior has been reported previously for Kevlar [3, 10]. The micropore volume is very low and indicates a small relationship between the increase in the BO and the increase of it. On the contrary, if we look at Table 1 it shows that physically activated fibers with steam of water present best surface areas and micropore volume similar to those reported previously $[3,10]$.

For the fibers activated with $\mathrm{H}_{3} \mathrm{PO}_{4}$, there is an isotherm type III $\left(10 \% \mathrm{H}_{3} \mathrm{PO}_{4}\right.$, and impregna-

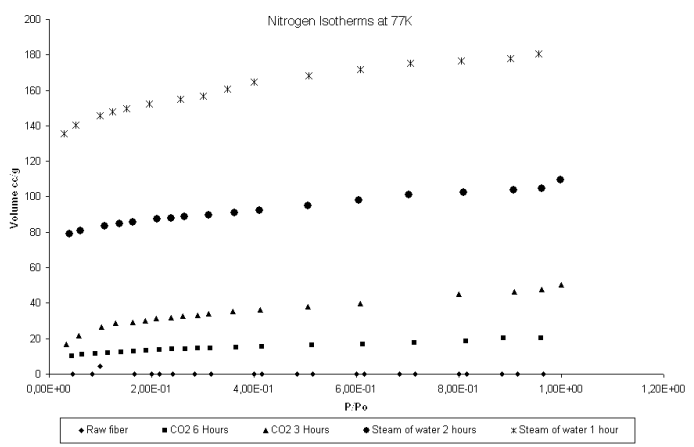

Figure 5. $\mathrm{N}_{2}$ Isotherms at $77 \mathrm{~K}$ for the activated fibers at $850^{\circ} \mathrm{C}$ with $\mathrm{CO}_{2}$ and steam of water.

Table 1. Textural parameters for fibers activated physically.

\begin{tabular}{c|c|c|c|c}
\hline Sample & $\begin{array}{c}\text { Activation } \\
\text { time }\end{array}$ & $\begin{array}{c}\text { Burn Off } \\
\%\end{array}$ & $\begin{array}{c}\text { BET area } \\
\mathrm{m}^{2} / \mathrm{g}\end{array}$ & $\begin{array}{c}\text { Micropore volume cc/g } \\
\text { (DR model) }\end{array}$ \\
\hline $\mathrm{I}$ & 0 & 0 & 0.0072 & 0 \\
\hline $\mathrm{CO}_{2}$ Activated fiber & 3 Hours & 19.69 & 100.598 & 0.0546 \\
\hline $\mathrm{CO}_{2}$ Activated fiber & 6 Hours & 76.67 & 43.645 & 0.0203 \\
\hline $\begin{array}{c}\text { Steam of water } \\
\text { activated fiber }\end{array}$ & 1 hour & 29.42 & 458.517 & 0.2399 \\
\hline $\begin{array}{c}\text { Steam of water } \\
\text { activated fiber }\end{array}$ & 2 hours & 93.75 & 251.787 & 0.1370 \\
\hline
\end{tabular}


Table 2. Textural parameters for fibers activated with phosphoric acid.

\begin{tabular}{c|c|c|c}
\hline$\%$ Phosphoric acid $\mathrm{p} / \mathrm{v}$ & Yield & $\begin{array}{c}\text { B.E.T area } \\
\mathrm{m}^{4} / \mathrm{g}\end{array}$ & $\begin{array}{c}\text { Micropore volume (D.Rmethod } \\
\mathrm{cc} / \mathrm{g})\end{array}$ \\
\hline $\begin{array}{c}10 \text { (Impregnated at } \\
\text { room temperature) }\end{array}$ & 53.40 & 5.64 & 0.00265 \\
\hline $\begin{array}{c}20 \text { (Impregnated at } \\
\text { room temperature) }\end{array}$ & 67.66 & 11.03 & 0.00511 \\
\hline $\begin{array}{c}30 \text { (Impregnated at } \\
90^{\circ} \mathrm{C} \text { by } 7 \text { hours) }\end{array}$ & 68.42 & 19.37 & 0.00646 \\
\hline $\begin{array}{c}30 \text { (Impregnated in } \\
\text { rotary evaporator) }\end{array}$ & 67.36 & 403.32 & 0.213 \\
\hline
\end{tabular}

tion at room temperature) indicating low adsorbate adsorbent interactions. The rest are Type II: 20 and $30 \% \mathrm{H}_{3} \mathrm{PO}_{4}$ where the last was held at $90^{\circ} \mathrm{C}$ by 7 hours (See Fig. 6a). The difference is obvious and corroborates what data shows. Table 2 reports the textural parameters for the fibers prepared. The surface area is low and the micropore volume indicates little activation on the material.

However, Fig. $6 \mathrm{~b}$ with help from Table 2 shows the isotherm and textural data for fiber impregnated in the rotary evaporator. A significant change in the development of the area and porosity in the fibers is observed. This system allows a homogeneous impregnation thanks to the rotation

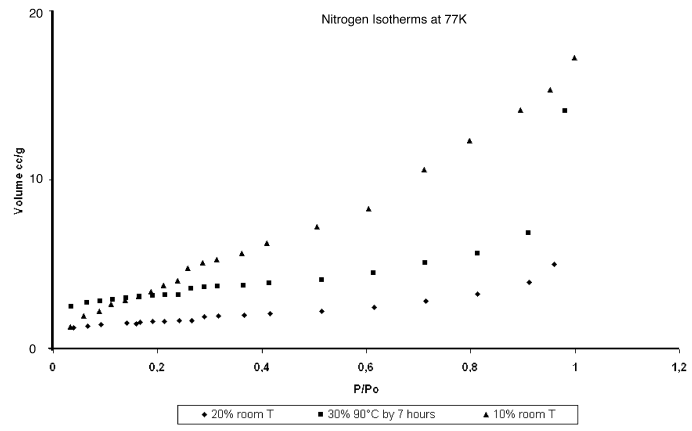

Figure 6a. Adsorption Isotherms for the fibers chemically activated.

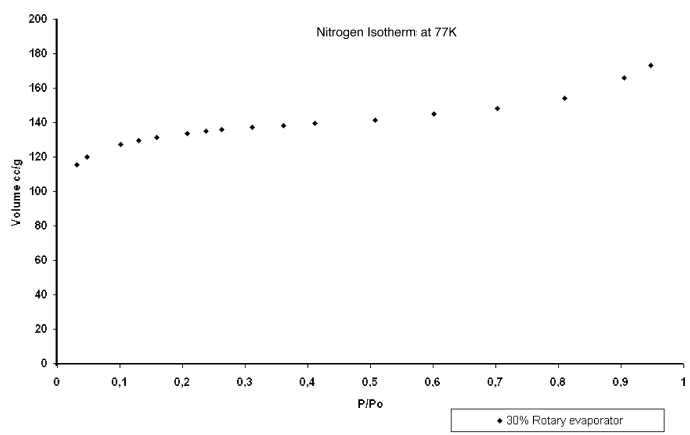

Figure 6b. $\mathrm{N}_{2}$ isotherm for the fiber impregnated in the rotary evaporator. of the permanent acid salts used; that factor coupled with the temperature and time used ( 2 hours), proves to be the most appropriate.

\section{Scanning electron microscopy (SEM)}

Noting Fig. 7 and 8 can be seen microscopies for physically activated fibers. It is noted that despite the process to which they have been subjected the fibers preserve their shape and structure indicating good characteristics of the material
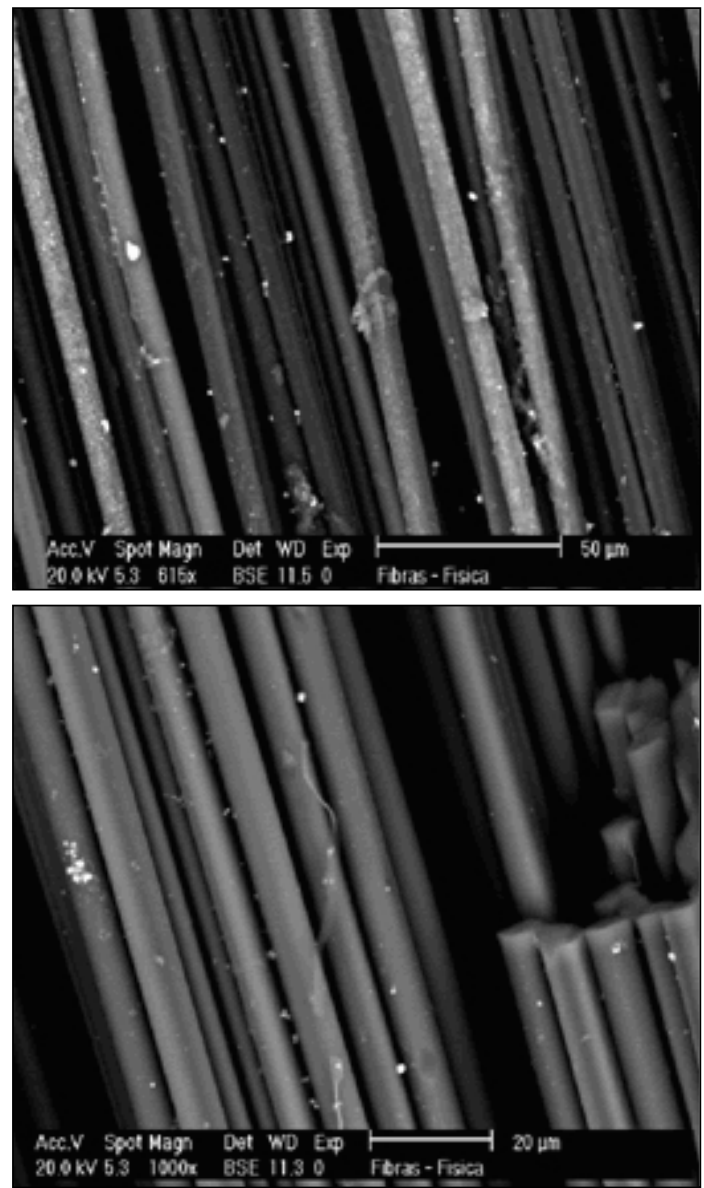

Figures 7 and 8. SEM for samples activated physically. 
to resist high temperatures and the attack of an activating agent. At first glance, the sample shows a single fiber, but to put it on a microscope shows that internally each fiber is composed of "micro fibers"; along with porosity, these are the ones who make of the carbon fibers materials with good capabilities of adsorption and facilitate adsorbents the spread of an adsorbate.

Similarly, Fig. 9 (increased 245x) shows that the structure of the fiber is retained although to a lesser extent with respect to those activated physically. The agglomeration phenomenon is attributable to progressive Kevlar depolymerization by reaction with $\mathrm{H}_{3} \mathrm{PO}_{4}$ [5]. This behavior increases with the concentration of the acid used. Therefore, although increasing the impregnation ratio is beneficial regarding porosity development; the use of large amounts of activating agent is harmful for obtaining ACFs, since the fibrous morphology is progressively lost. . Meanwhile, Figures 10 and 11 show some structures that indicate changes associated with some kind of action of the phosphoric acid and carbonization on Kevlar fibers.

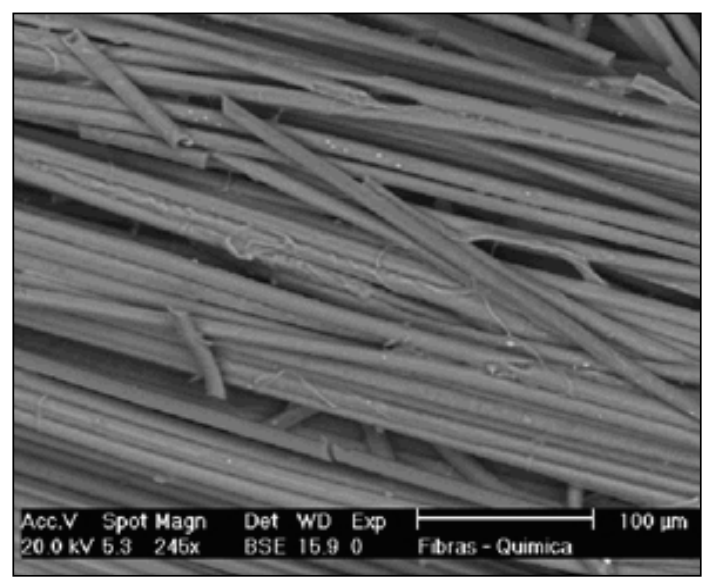

Figure 9. SEM for samples chemically activated.
In both fibers, (the physically and chemically activated) can be seen the emergence of some white spots [11] which can be associated with the presence of small traces of metals result of the synthesis of the precursor material which contribute somewhat to the processes that con-
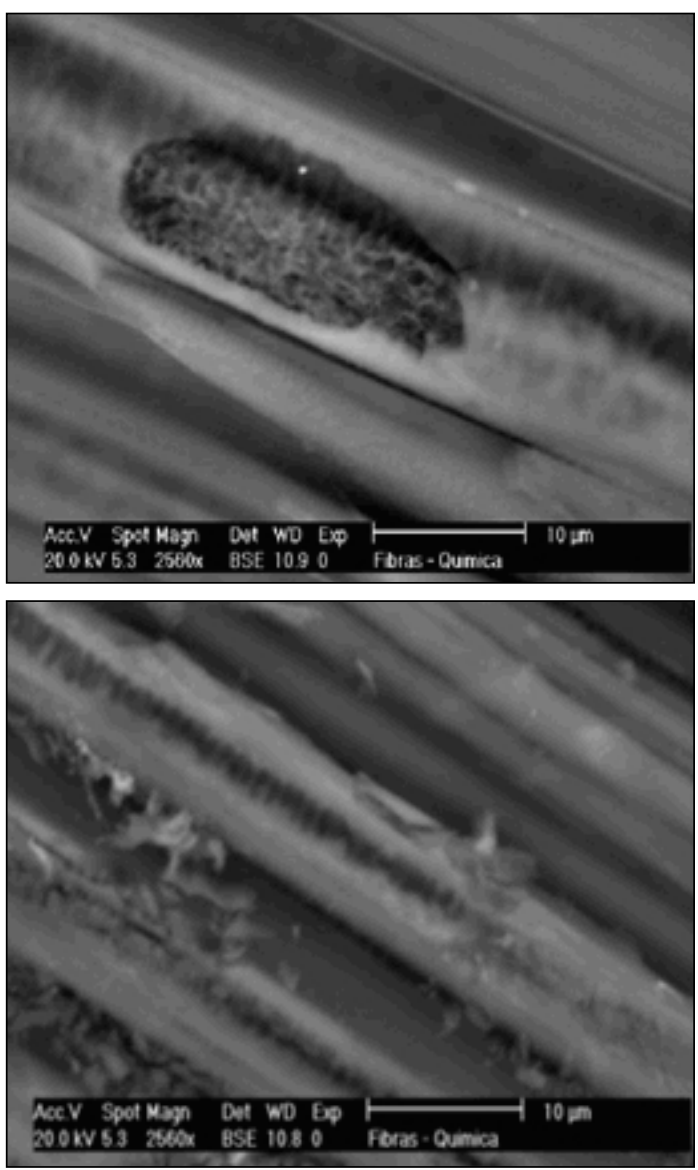

Figures 10 and 11. EM for samples chemically activated at $2560 x$.

Table 3. Parameters assessed in the immersion calorimetries for physically activated carbon fibers.

\begin{tabular}{|c|c|c|c|c|c|c|c|c|c|c|}
\hline$\frac{\frac{\Phi}{O}}{\frac{O}{E}}$ & $\stackrel{\mathscr{\varrho}}{\underline{E}}$ & - & $>$ & ه & $\begin{array}{l}3 \\
.0 \\
\frac{0}{ \pm} \\
\frac{d}{W}\end{array}$ & 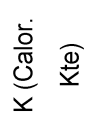 & 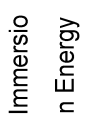 & $\frac{\underline{E}}{\frac{E}{T}}$ & 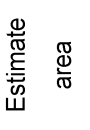 & 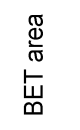 \\
\hline Units & $\mathrm{s}$ & $A$ & $\mathrm{~V}$ & $V^{*} I$ & $\mathrm{~J}$ & $J^{*} \mathrm{~s} / \mathrm{v}$ & $\mathrm{J}$ & $\mathrm{J} / \mathrm{g}$ & $\mathrm{m}^{2} / \mathrm{g}$ & $\mathrm{m}^{2} / \mathrm{g}$ \\
\hline $\begin{array}{l}\text { Steam } \\
\text { of water } \\
1 \text { hour. }\end{array}$ & 53.34 & 1 & 0.0108 & 0.0108 & 2.1336 & 1058.81 & 3.113 & 86.97 & 626.3 & 458.1 \\
\hline $\begin{array}{l}\text { Steam } \\
\text { of water } \\
2 \text { hours. }\end{array}$ & 93.25 & 1 & 0.0108 & 0.0108 & 1.0071 & 1366.25 & 0.727 & 14.52 & 180.1 & 251.7 \\
\hline
\end{tabular}


ducted during the transformation of Kevlar fibers into activated carbon fibers.

\section{Immersion calorimetry in benzene}

Table 3 reveals the experimental immersion enthalpy in benzene for physically activated fibers. The data shows that the immersion enthalpy increases with the increase in the BET area. Likewise, the estimated area from the method is different from that obtained on the BET model but is within an acceptable range taking into account the size of the molecules of $\mathrm{N}_{2}$ and $\mathrm{C}_{6} \mathrm{H}_{6}(0.36$ and $0.37 \mathrm{~nm}$, respectively) and the interactions of the same with the microporosity present in the fibers [12]. Figure 12 shows the charts for the calorimetries undertaken.

\section{Yields and Burn off (BO)}

In Table 4 is possible to see the yield and BO at different times and temperatures. On the other hand, figure 13 represents the relationship between $\mathrm{BO}$ and temperature. With regard to yield, it shows that the values are not affected with the increase of temperature (average $31.79 \%$ ) ; this behavior is consistent with the findings of the crude fiber TGADTA taking into account that beyond the $700^{\circ} \mathrm{C}$ curve does not suffer big falls. Likewise, yields are below $50 \%$ confirming that in this step will be the largest mass loss. The $\mathrm{BO}$ of the fibers shows that



the highest values are obtained at $850^{\circ} \mathrm{C}$, plus the time of activation increase it. Figure 14 shows the relationship between $\mathrm{BO}$ and time of activation at $850^{\circ} \mathrm{C}$. The behavior of the material is to increase the $\mathrm{BO}$ as the increase of the activation time.

Table 5 and Figure 15 respectively present the yield of the chemical activation. The yields indicate that the increase in the concentration of phosphoric acid increases the efficiency of the process. Activation requires the removal of hydrogen and oxygen present in the precursor material, phosphoric acid acts as desiccant enabling and facilitating this process. The increase on the yield with the increase in the concentration has limit, for example, if is used very high concentrations of acid it deteriorates the structure of the fibers; they agglomerate and lose its shape.

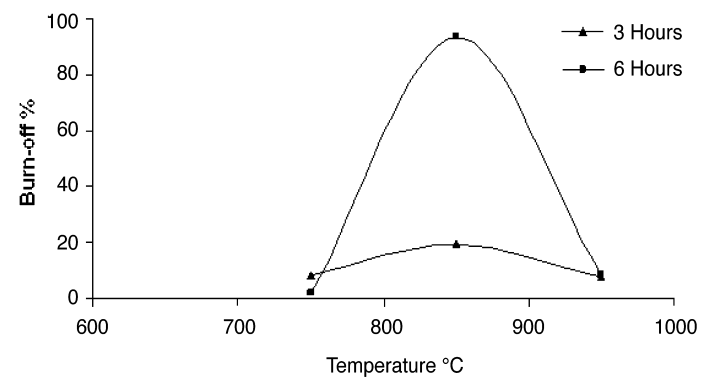

Figure 13. Relationship between temperature and BO.

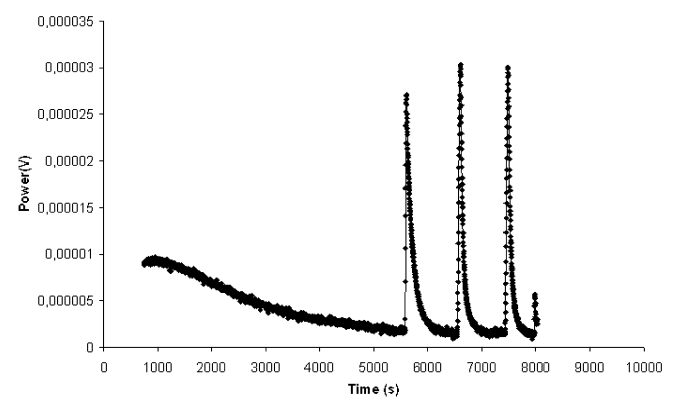

Calorimetry for 1 HOUR

Figure 12. Immersion calorimetries in benzene for physically activated fibers.

Table 4. BO performance of the fibers physically activated.

\begin{tabular}{c|c|c|c|c|c}
\multicolumn{5}{c}{ ACTIVATION } \\
\hline Sample & Temperature & Yield $\%$ & Temperature & Time & Burn Off \% \\
\hline 1 & $800^{\circ} \mathrm{C}$ & $34.04 \%$ & $750^{\circ} \mathrm{C}$ & $6 \mathrm{~h}$ & $8.57 \%$ \\
\hline 2 & $800^{\circ} \mathrm{C}$ & $31.23 \%$ & $750^{\circ} \mathrm{C}$ & $3 \mathrm{~h}$ & $8.11 \%$ \\
\hline 3 & $900^{\circ} \mathrm{C}$ & $30.05 \%$ & $850^{\circ} \mathrm{C}$ & $6 \mathrm{~h}$ & $76.67 \%$ \\
\hline 4 & $900^{\circ} \mathrm{C}$ & $29.87 \%$ & $850^{\circ} \mathrm{C}$ & $3 \mathrm{~h}$ & $19.7 \%$ \\
\hline 5 & $1000^{\circ} \mathrm{C}$ & $32.79 \%$ & $900^{\circ} \mathrm{C}$ & $6 \mathrm{~h}$ & $8.66 \%$ \\
\hline 6 & $1000^{\circ} \mathrm{C}$ & $32.76 \%$ & $950^{\circ} \mathrm{C}$ & $3 \mathrm{~h}$ & $8.62 \%$ \\
\hline
\end{tabular}


Table 5. Yields for fibers chemically activated.

\begin{tabular}{c|c|c|c|c}
\hline Sample & $\begin{array}{c}{\left[\mathrm{H}_{3} \mathrm{PO}_{4}\right.} \\
\mathrm{p} / \mathrm{v}\end{array}$ & $\begin{array}{c}\text { Carbonization } \\
\text { temperature }\end{array}$ & $\begin{array}{c}\text { Yield (after } \\
\text { carbonization) } \%\end{array}$ & $\begin{array}{c}\text { Yield (after } \\
\text { washing)\% }\end{array}$ \\
\hline 1 & $10 \%$ & $700^{\circ} \mathrm{C}$ & $53.40 \%$ & $47.07 \%$ \\
\hline 2 & $20 \%$ & $700^{\circ} \mathrm{C}$ & $67.66 \%$ & $59.23 \%$ \\
\hline 3 & $30 \%$ & $700^{\circ} \mathrm{C}$ & $68.42 \%$ & $52.78 \%$ \\
\hline
\end{tabular}

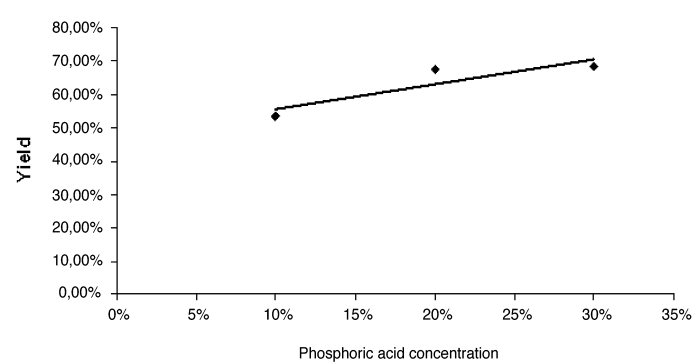

Figure 15. Relationship between concentration and yield.

Comparing yields in Tables 3 and 4, the high values correspond to the chemical activations. The presence of phosphoric acid in the fibers suggests that this activant agent somehow controls the contraction of precursor material, as well as promotes the dehydration and thus the resulting mass of the resulting char.

\section{Conclusions}

Activated carbon fibers from Kevlar can be synthesized through activations with $\mathrm{CO}_{2}$ and steam of water. The best surface areas and micropore volumes are obtained using steam of water; $\mathrm{CO}_{2}$ not optimally active Kevlar fibers with the used conditions. Moreover, the structure and morphology of the fibers is preserved. The activation process involves regrouping and reactions of depolymerization, evidenced in the infrared spectrum and in the values of yield and BO. There are optimum times and temperatures which are conducive results. Likewise, immersion enthalpies for fibers physically activated are proportional with BET areas and similar to those obtained from the performance of the nitrogen isotherms.

Similarly, activated carbon fibers can be obtained through chemical activations using agents such as phosphoric acid. The way to carry out the impregnation is an important factor; for Kevlar, the best areas and micropore volumes are obtained thought impregnations using a rotary evaporator which guarantees constant shaking, optimum temperatures and times guaranteeing good results. The increase in the concentration facilitates the activation processes by increasing the yield, while agglomerate the fibers deteriorate somewhat its structure. A middle ground is ideal.

In conclusion and by comparing the two processes can be said that the physical activation develops the best surface areas and micropore volumes regard to the chemical activation for Kevlar. Moreover, the structure of the fiber is deteriorating with a chemical activation than with a physical, it joined the chemical activation process involves taking a further step: the wash. Samples physically and chemically activated which presents best surface areas and pore diameters good makes materials for striking selective adsorption.

Received 25 October 2007

Accepted 04 December 2007

\section{References}

[1] M.P. Cal, M.J. Rood, M.J., S.M. Larson. Gas. Sep. Purif. 10 (2) (1996) 110.

[2] H. Pignon, C. Brasquet, P. Le Cloirec. Water Science and Technology. 42 (2000), 355.

[3] M.C Blanco López, A. Martínez Alonso, J.M.D Tascón. Micropor. Mesopor. Mater. 34 (2000) 171.

[4] F. Suarez, A. Martínez, J.M.D. Tascón. Carbon. 42 (2004) 1419.

[5] J.A. Maciá Argullo, B.C.Moore, D. Cazorla Amorós, A. Linares Solano. Carbon. 42 (2004) 1367.

[6] F. Suarez, A. Martínez, J.M.D. Tascón. Micropor. Mesopor. Mater. 75 (2004) 73.

[7] M.C Blanco López, A. Martínez Alonso, J.M.D Tascón. Carbon. 38 (2000) 1177.

[8] Kevlar technical guide. www.Du Pont.com

[9] S. Villar rodil, A. Martinez Alonso. J.M.D Tascón. Analytical and applied pyrolysis. 58-59 (2001) 105.

[10] M.C. Blanco López, A. Martinez Alonso, J.M.D.Tascón. Carbon 38 (2000) 1177.

[11] P.J.M Carrot, J.V.M Nabais, M.M.L Ribeiro, J.A. Pajares. Carbon 39 (2001) 1543.

[12] S. Villar Rodil. R. Denoyel, J. Rouquerol. A. Martinez Alonso. J.M.D.Tascón. Carbon 40 (2002) 1369. 